\title{
Thermal signal propagation in soils in Romania: conductive and non-conductive processes
}

\author{
C. Demetrescu ${ }^{1}$, D. Nitoiu ${ }^{1}$, C. Boroneanţ ${ }^{2}$, A. Marica ${ }^{2}$, and B. Lucaschi ${ }^{2}$ \\ ${ }^{1}$ Institute of Geodynamics, Bucharest, Romania \\ ${ }^{2}$ National Meteorological Administration, Bucharest, Romania \\ Received: 21 February 2007 - Published in Clim. Past Discuss.: 8 March 2007 \\ Revised: 15 August 2007 - Accepted: 16 October 2007 - Published: 2 November 2007
}

\begin{abstract}
Temperature data recorded in 2002 and 2003 at 10 stations out of the 70 available in the Romanian automatic weather stations network are presented and analyzed in terms of the heat transfer from air to underground. The air temperature at $2 \mathrm{~m}$, the soil temperatures at $0,5,10,20,50$ and $100 \mathrm{~cm}$ below the surface as well as rain fall and snow cover thickness have been monitored. The selected locations sample various climate environments in Romania. Preliminary analytical modelling shows that soil temperatures track air temperature variations at certain locations and, consequently, the heat transfer is by conduction, while at other stations processes such as soil freezing and/or solar radiation heating play an important part in the heat flux balance at the air/soil interface. However, the propagation of the annual thermal signal in the uppermost one meter of soil is mainly by conduction; the inferred thermal diffusivity for 8 stations with continuous time series at all depth levels ranges from 3 to $10 \times 10^{-7} \mathrm{~m}^{2} \mathrm{~s}^{-1}$.
\end{abstract}

\section{Introduction}

Reconstruction of past climate changes from geothermal data has proven, in the last decade, to be an additional source of information to complement meteorological and proxy records of climatic change (Harris and Chapman, 1998; Huang et al., 2000; Şerban et al., 2001; Beltrami, 2002; Pollack and Smerdon, 2004; González-Rouco et al., 2006; Stevens et al., 2007). The interest in this method lies in the fact that it examines a direct measure of temperature, free of problems caused by the conversion of proxy data to temperatures.

The controversy regarding the magnitude of climate variability during the last millennium revealed from borehole

Correspondence to: C. Demetrescu

(crisan@geodin.ro) inversions and proxy data (Briffa and Osborn, 2002; Esper et al., 2002, 2004; McIntyre and McKitrick, 2005; Hegerl et al., 2007) triggered investigations of the basic assumptions of the geothermal method, i.e. a purely conductive regime and a strong air-soil temperature coupling (González-Rouco et al., 2003, 2006; Mann et al., 2003; Mann and Schmidt, 2003; Chapman et al., 2004; Pollack and Smerdon, 2004; Pollack et al., 2005).

The role of a variety of processes, such as snow cover variation, land cover changes and precipitation, influencing the relationship between air and ground temperatures and thus the ground surface energy transfer, has been widely investigated (Putnam and Chapman, 1996; Schmidt et al., 2001; Sokratov and Barry, 2002; Stieglitz et al., 2003; Bartlett et al., 2004; Smerdon et al., 2004, 2006; Bartlett et al., 2005; Nitoiu and Beltrami, 2005; Trenberth and Shea, 2005).

Although the Earth's response to the energy transfer at the surface is related to the surface air temperature (SAT), the ground surface temperature (GST) is an integral of the effects of air temperature variation, vegetation and snow cover variations, phase changes and solar radiation changes at the soil surface (Oke, 1987). The process of heat transfer within soils is important for correct interpretation of the climatic signal extracted from geothermal data. There are a number of studies at mid-latitude, from where most of the borehole temperature logs come (e.g. Beltrami and Kellman, 2003; Smerdon et al., 2003, 2006).

Using a one-dimensional finite difference numerical model to generate the soil temperature variations in the upper first meter of the ground, Schmidt et al. (2001) and Beltrami (2001) showed that during winter, the process of heat conduction is disturbed by the presence of snow cover and by the freezing and melting of soil water. Mainly in open field areas, processes arising from precipitation, water movement or infiltration influence the subsurface heat transfer regime throughout all seasons. This leads to non-conductive heat transport that affects the soil temperature profiles (Trenberth

Published by Copernicus Publications on behalf of the European Geosciences Union. 


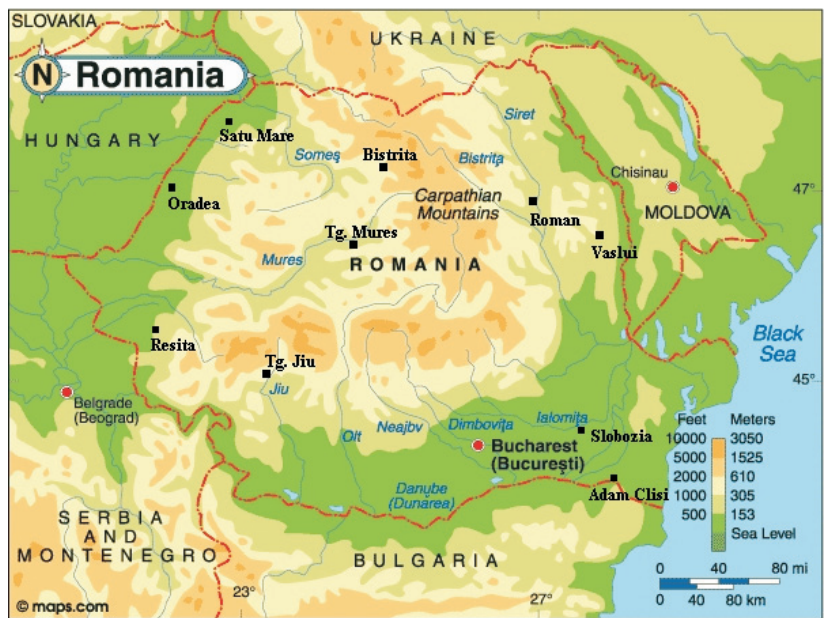

Fig. 1. Location of the 10 stations of the Romanian automatic weather stations network (black squares) used in the present study (The Romanian map was modified from www.maps.com).

Table 1. Mean annual climatic conditions in the 2003-2004 period at the meteorological stations.

\begin{tabular}{lcccc}
\hline Station & SAT $\left({ }^{\circ} \mathrm{C}\right)$ & GST $\left({ }^{\circ} \mathrm{C}\right)$ & Rain fall $(\mathrm{cm})$ & Snow fall $(\mathrm{cm})$ \\
\hline Adamclisi & 11.07 & 11.88 & 57.50 & 35.4 \\
Bistriţa & 8.72 & 9.66 & 60.76 & 95.65 \\
Oradea & 10.60 & 11.14 & 61.92 & 48.55 \\
Reşiţa & 10.58 & 10.62 & 77.87 & 30.60 \\
Roman & 9.21 & 10.47 & 46.32 & 34.15 \\
Satu Mare & 9.93 & 11.10 & 57.49 & 46.90 \\
Slobozia & 11.01 & 12.60 & 54.51 & 36.90 \\
Tg. Jiu & 10.91 & 12.15 & 82.80 & 84.90 \\
Tg. Mureş & 9.05 & 10.19 & 55.94 & 72.35 \\
Vaslui & 9.75 & 10.77 & 52.16 & 58.45 \\
\hline
\end{tabular}

and Shea, 2005). These processes make modelling of the near surface ground temperatures more difficult.

In the last few years, a new automatic weather station network in Romania has been established and is likely to produce a continuous and homogeneous data set for a territory characterized by lateral climatic variability (Ţîştea et al., 1979; Boroneanţ et al., 2004). This dataset can be used to clarify some of the aspects of the heat transfer at the Earth's surface. In the present paper we analyze the heat transfer in the uppermost meter of soil using air and soil data temperature recorded daily at 10 stations from Romania during a two year period (2003-2004).

We examine the character of the soil heat transfer regime at two temporal scales: firstly by looking at the fit between the soil temperatures simulated with a simple conduction model and the measured data at the inter-daily temporal scale, and secondly, at the annual variation scale, in terms of perfect sinusoidal functions of time describing the observed varia-

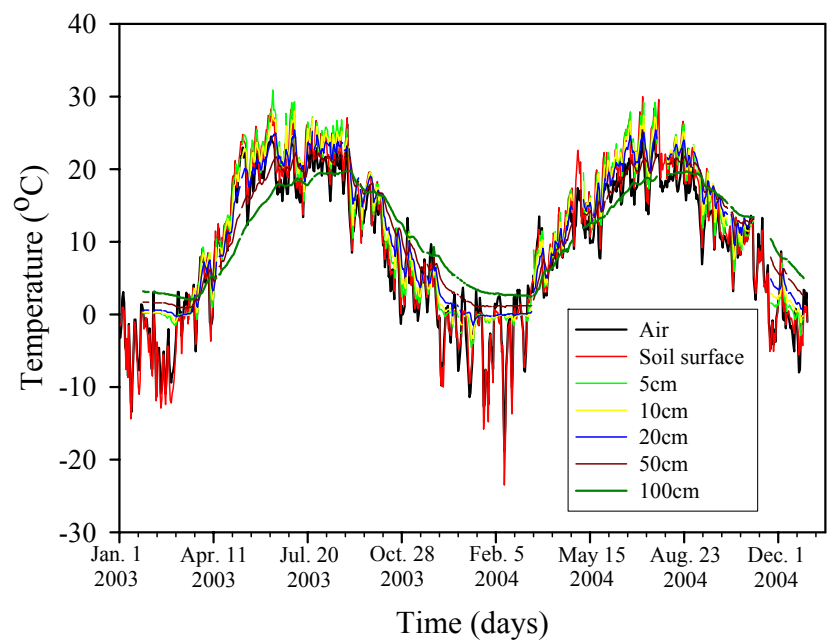

Fig. 2. Daily-averaged temperatures for Bistriţa for the years 2003 and 2004: air (black line), soil surface (red), $5 \mathrm{~cm}$ within soil (light green), $10 \mathrm{~cm}$ (yellow), $20 \mathrm{~cm}$ (blue), $50 \mathrm{~cm}$ (brown) and $100 \mathrm{~cm}$ (dark green).

tions. An effective thermal diffusivity of the upper meter of soil was obtained.

\section{Data}

The Romanian National Meteorological Administration network comprises 70 automatic weather stations evenly distributed over the country. Each station is equipped with MAWS 301 Vaisala measuring systems that are designed to measure the atmospheric pressure, air temperature, relative humidity, wind speed and direction, liquid precipitations, as well as global, net and diffuse radiation. At mountain weather stations an ultrasonic device is used to measure the snow depth; at low altitude stations, the soil temperature is measured using a QMT 107 system. The soil temperature sensor QMT 107 is constructed of a glass fiber tube filled with epoxy in which resistive platinum probes (Pt-100) are embedded at appropriate locations. The accuracy of the air and soil temperature records is better than $\pm 0.2 \mathrm{~K}$. All stations are located in open field and thus exposed directly to the sun.

In this study, air $(2 \mathrm{~m})$ and soil temperature at six depth levels $(0,5,10,20,50,100 \mathrm{~cm})$ recorded at 10 locations in the Romanian automatic weather station network (Fig. 1), in 2003 and 2004, were used. The stations were chosen to uniformly cover the Romanian territory and thus to sample the main climatic areas of the territory. The mean annual SAT and GST, as well as the total annual precipitation and snow thickness for each meteorological station for 2003 and 2004 are given in Table 1. The mean daily SATs and GSTs were 

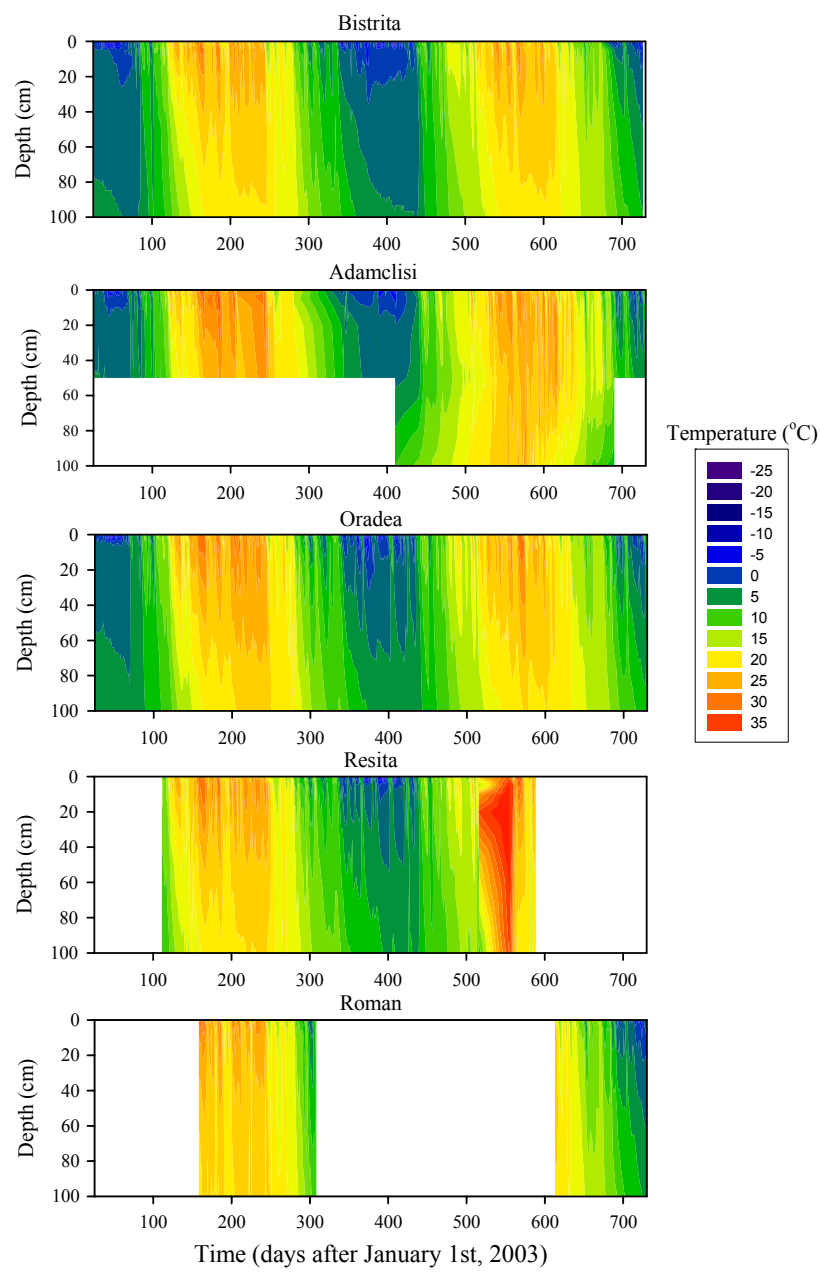

Fig. 3. Isotherms of daily-averaged temperatures for Bistriţa, Adamclisi, Oradea, Reşiţa and Roman stations, for the years 2003 and 2004.

calculated by averaging the temperature values measured at 1 a.m., 7 a.m., 1 p.m. and 7 p.m., local time.

It is generally accepted that GST is higher than SAT (Beltrami and Kellman, 2003), and the Romanian stations make no exception as it can be seen from Table 1. This was discussed by Demetrescu et al. (2006) in greater detail. However, problems related to the definition of the ground surface temperature in the measuring system, which we became aware of later and have not been clarified yet, prevent us using the corresponding data set in the present paper.

The analysis was performed for each of the ten stations, but in the following we show results only for Bistriţa because it has continuous records available. The daily average temperatures recorded at Bistriţa are illustrated in Fig. 2 as time series. The daily average temperatures recorded at all stations are illustrated in Figs. 3 and 4 as isotherms on temperature/depth/time plots. One can easily see the attenu-
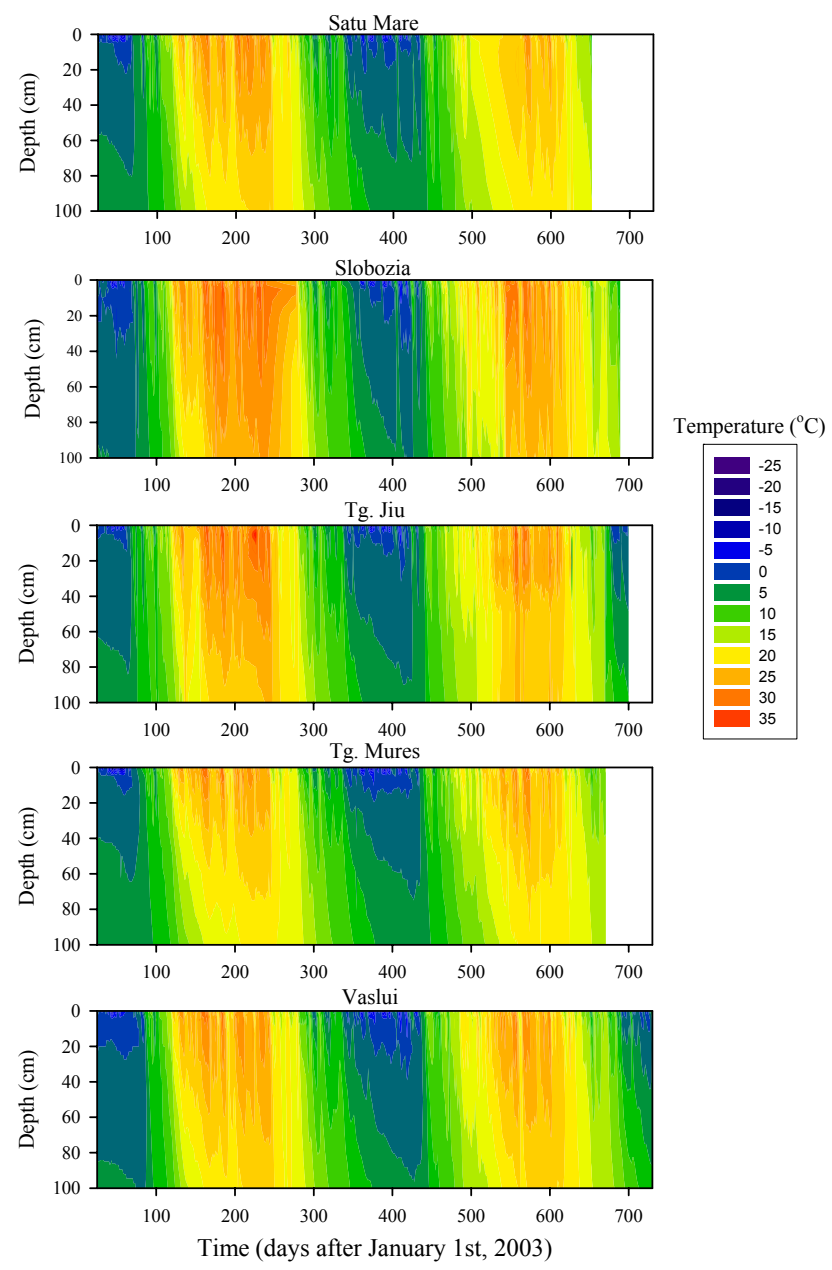

Fig. 4. Isotherms of daily-averaged temperatures for Satu Mare, Slobozia, Tg. Jiu, Tg. Mureş and Vaslui stations, for the years 2003 and 2004.

ation of the high frequency temperature fluctuations and the attenuation of the annual variation as the signal is propagated into the ground, the phase shift with depth of the temperature wave, as well as the "heat-valve" effect (heat flows downwards in summer, while in winter it flows towards the Earth surface) and the zero curtain effect (negative temperatures cannot be found in the ground until the water in the soil completely freezes) (Beltrami, 2001; Kane et al., 2001). Large periods of missing data can be noticed for Adamclisi, Reşiţa and Roman stations.

Throughout the year, many non-conductive processes influence the heat transfer at shallow depths. During winter, phase changes occurring at the release or absorption of heat through freezing or melting respectively, lead to a decoupling between surface and deep soil temperatures. Figure 5 shows a comparison of the daily mean air temperatures measured at Bistriţa during the winter season of 2003-2004 and the beginning of spring (spanning approximately from the end of 

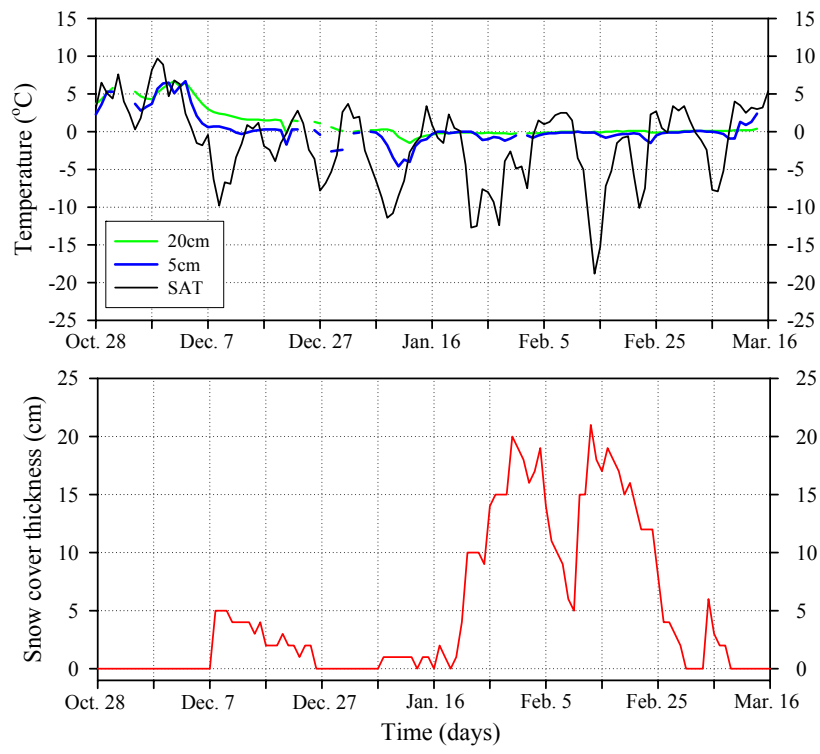

Fig. 5. Daily soil temperature records for the indicated depths at Bistriţa station for the winter season 2003-2004. The bottom panel shows the daily snow thickness $(\mathrm{cm})$ for the same period of time.

October 2003 until middle March, 2004) with the soil temperatures recorded at 5 and $20 \mathrm{~cm}$ in soil. Daily snow cover thickness for the same period of time is represented in the bottom panel of Fig. 5.

The zero-curtain effect is obvious in days when no or little $(1-2 \mathrm{~cm})$ snow cover is present on the ground. For the time interval 27 December- 16 January, as SAT decreases below $0^{\circ} \mathrm{C}$ and the surface layer is freezing, latent heat is released, heat that delays the downward penetration of the freezing front (Kane et al., 2001). As long as the volume of water contained in the soil does not freeze, the temperature is kept constant near zero; the transition layer is called zero-curtain (Kane et al., 2001). The layer of soil beneath this region is isolated from the cold temperature of the soil surface. Once the soil water is converted to ice, the freezing front propagates fast (thermal conductivity of ice is $2.25 \mathrm{Wm}^{-1} \mathrm{~K}^{-1}$ while the thermal conductivity of water at room temperature is $0.60 \mathrm{Wm}^{-1} \mathrm{~K}^{-1}$ (Carslaw and Jaeger, 1959)) through conduction to deeper levels. Thus, as the air temperature decreases below the freezing level on 3 January 2004, because of the zero-curtain effect the freezing front penetrates at $5 \mathrm{~cm}$ only 2 days later, on 5 January 2004, and the soil temperature at $20 \mathrm{~cm}$ decreases below $0^{\circ} \mathrm{C}$ only on 9 January 2004 . The magnitude of the cold front propagating downward decreases both because of the zero-curtain and the low thermal diffusivity of the soil.

The air and deep soil temperatures relationship is also influenced, during the winter months, by the presence of snow cover (Grundstein et al., 2005). At Bistriţa station (see Fig. 5), the ground was covered by a snow layer having a thickness of at least $5 \mathrm{~cm}$ for the time period spanning from

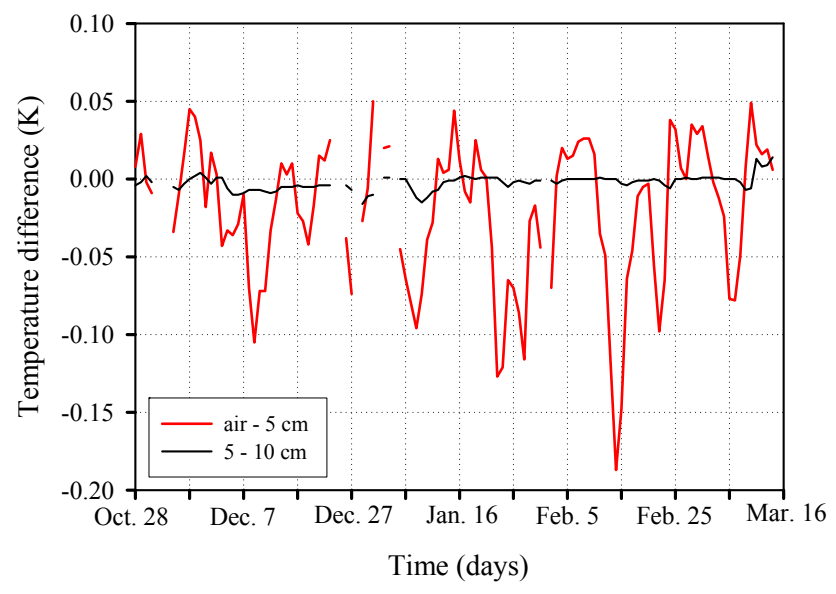

Fig. 6. Variation in time of the temperature differences for SAT$5 \mathrm{~cm}$ (red line) and for 5-10 cm (black line) layers, at Bistriţa station for the winter season 2003-2004.

20 January 2004 to 25 February 2004. During this period, while SAT decreased to as much as $-18.8^{\circ} \mathrm{C}$, because of the thick layer of snow and because of the buffering effect of the upper layer of soil, the $5 \mathrm{~cm}$ soil temperature has never decreased to less than $-1.5^{\circ} \mathrm{C}$, and the $20 \mathrm{~cm}$ soil temperature has not decreased below $-0.1^{\circ} \mathrm{C}$. In contrast, in periods without snow cover, the temperatures at $5 \mathrm{~cm}$ and $20 \mathrm{~cm}$ decreased to $-4.6^{\circ} \mathrm{C}$ and $-1.5^{\circ} \mathrm{C}$ respectively, when SAT attained a minimum of only $-11.4^{\circ} \mathrm{C}$.

Figure 6 shows the daily temperature differences calculated for the period 28 October 2003 and 15 March 2004 using the measured SAT and soil temperatures at $5 \mathrm{~cm}$ (red line). For comparison, Fig. 6 also shows (black line) the daily temperature differences between 5 and $10 \mathrm{~cm}$. The negative difference for the SAT- $5 \mathrm{~cm}$ layer clearly shows the isolation of the shallow soil from the surface temperature variations during the presence of the snow layer and the cooling of the ground during the zero-curtain period. The greatest negative temperature difference for the $5-10 \mathrm{~cm}$ layer is on 9 January 2004 and shows the net cooling of the ground after the closure of the zero-curtain period (Romanovsky and Osterkamp, 2000).

\section{Heat transfer regime in the subsurface}

\subsection{Inter-daily variation: analytical modelling using step} functions

In a 1-D case and a purely conductive medium, variations of surface temperature propagate into the ground according to the equation:

$$
\frac{\partial T(z, t)}{\partial t}=\kappa \frac{\partial^{2} T(z, t)}{\partial z^{2}}
$$




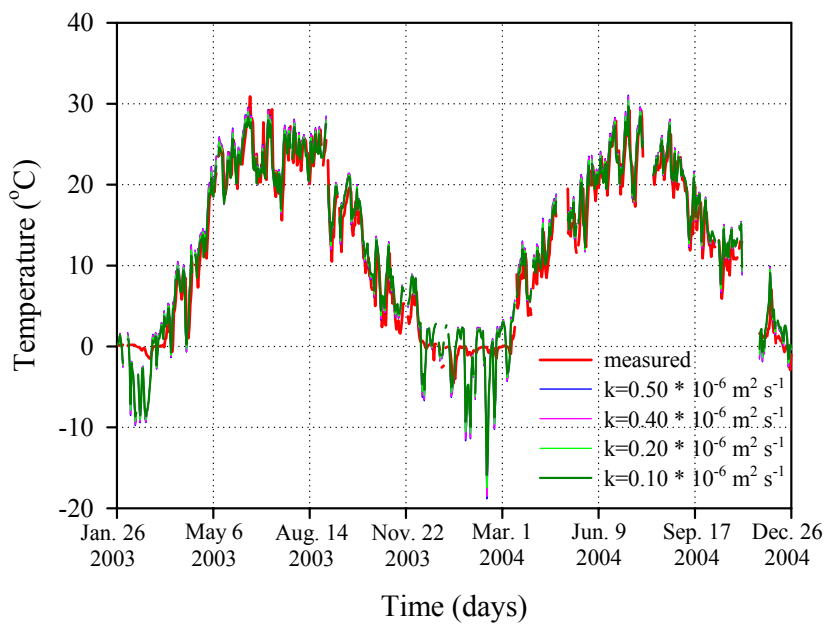

Fig. 7. Measured and modelled soil $5 \mathrm{~cm}$ temperature variations (daily averages) at Bistriţa for 2003 and 2004, using different values of thermal diffusivity for the $0-5 \mathrm{~cm}$ layer of soil.

where $\kappa$ is thermal diffusivity, and $z$ is depth taken positive downwards.

If the variations of soil surface temperature are modelled as a series of $N$ temperature changes, then the subsurface temperature signals from each step change are superimposed, and the temperature perturbation at depth $z$ is (Carslaw and Jaeger, 1959)

$T(z, t)=\sum_{n=1}^{N} T_{n}\left[\operatorname{erfc}\left(\frac{z}{2 \sqrt{\kappa t_{n}}}\right)-\operatorname{erfc}\left(\frac{z}{2 \sqrt{\kappa t_{n-1}}}\right)\right]$

where erfc is the complementary error function.

Modelling temperature variations with Eq. (2) and comparing them with the recorded temperatures can show deviations of the transfer of heat from a purely conductive regime. Taking as a forcing function the daily mean air temperature variation with respect to the first recorded temperature (26 January 2003), we generated the $5 \mathrm{~cm}$ soil temperature variation for thermal diffusivity ranging from $0.1 \times 10^{-6} \mathrm{~m}^{2} \mathrm{~s}^{-1}$ to $0.5 \times 10^{-6} \mathrm{~m}^{2} \mathrm{~s}^{-1}$ (see Fig. 7). Whatever thermal diffusivity value is used, the pure conduction model is not able to reproduce the actual temperatures recorded over an entire year interval. The lack of model sensitivity to the range of diffusivities is not surprising given the fact that the signal is diffusing through $5 \mathrm{~cm}$ of the subsurface and only very large differences in diffusivity would yield significantly different results. However, such a large range is not supported by observations on shallow soil diffusivity (e.g. Nitoiu, 2005; Yoshikawa et al., 2003). The discrepancy is large in winter and summer, when processes such as freezing or evaporation of the water content imply latent heat contribution and evapotranspirative cooling, respectively. A snow cover effect is superimposed on latent heat effects (see previous section). The
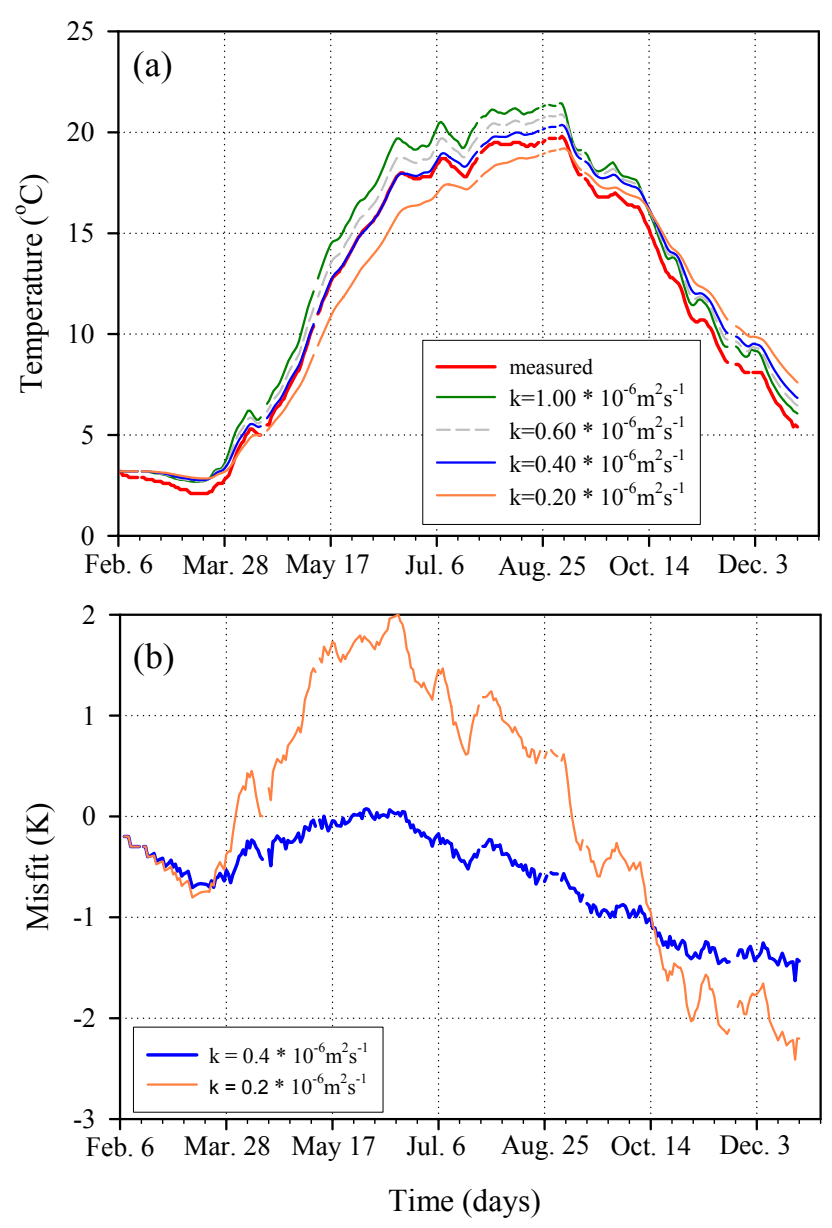

Fig. 8. (a) Heat transfer from 50 to $100 \mathrm{~cm}$ : measured and modelled daily $100 \mathrm{~cm}$ soil temperatures at Bistriţa for 2003, using different values of thermal diffusivity for the $50-100 \mathrm{~cm}$ layer of soil. (b) The misfit between the measured and modelled temperatures for two thermal diffusivities: $0.2 \times 10^{-6} \mathrm{~m}^{2} \mathrm{~s}^{-1}$ and $0.4 \times 10^{-6} \mathrm{~m}^{2} \mathrm{~s}^{-1}$.

effective thermal diffusivity of the first meter of soil varies accordingly.

At deeper levels processes mentioned above should diminish in importance. Taking as a forcing function the $50 \mathrm{~cm}$ soil temperature variation with respect to the measured value on 6 February 2003 (there are missing data in January between $5 \mathrm{~cm}$ and $50 \mathrm{~cm}$ depth due to recording system mal-function), we generated the soil temperature time series at $100 \mathrm{~cm}$ for 2003 , using different values for thermal diffusivity. Figure 8 shows a comparison of the modelled temperatures with the measured ones. The best fit (rms error of $\pm 0.77 \mathrm{~K}$ ) is obtained for a thermal diffusivity of $0.4 \times 10^{-6} \mathrm{~m}^{2} \mathrm{~s}^{-1}$, a value close to ones in Table 2, derived using sinusoidal functions (next section). Heat conduction is the dominant heat-transfer mechanism in the $50-100 \mathrm{~cm}$ depth range only in winter and spring. In summer and autumn, measured temperatures at $1 \mathrm{~m}$ are systematically lower than the predicted ones, probably because of evapotranspirative cooling and convection. 


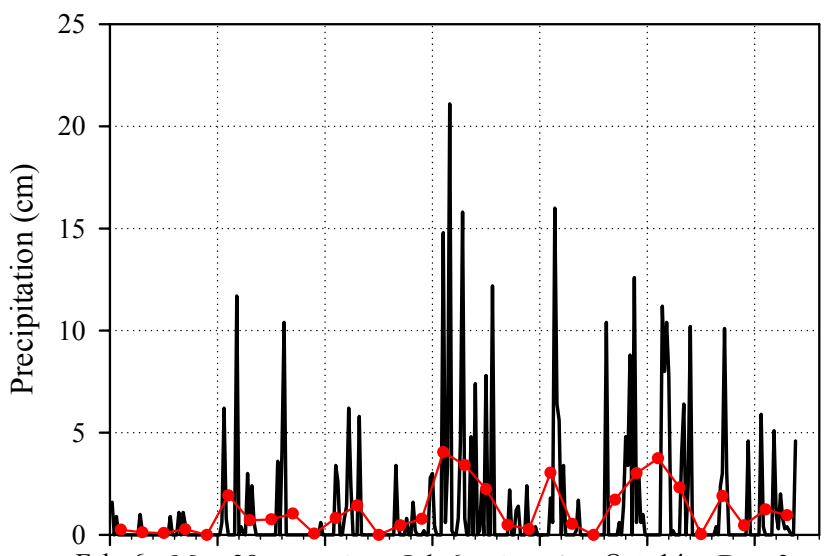

Feb. 6 Mar. 28 May 17 Jul. 6 Aug. 25 Oct. 14 Dec. 3

Time (days)

Fig. 9. Recorded precipitations at Bistriţa for 2003. With red line we represented the 10 days average precipitations.

Another factor which might intervene is the soil water content, which varies in the course of a year. A comparison with the recorded precipitation (Fig. 9) shows that the misfit increases after a significant increase in precipitation. Between 4 September and 15 October 2003, the best fit between the measured and modelled temperatures is obtained for a thermal diffusivity of $0.2 \times 10^{-6} \mathrm{~m}^{2} \mathrm{~s}^{-1}$ (rms difference of $\pm 0.50 \mathrm{~K}$ ), while the rms difference is $\pm 0.91 \mathrm{~K}$ when using a thermal diffusivity of $0.4 \times 10^{-6} \mathrm{~m}^{2} \mathrm{~s}^{-1}$. These show that, at the day to day scale, the effective thermal diffusivity of the first meter of soil is variable during the course of a year.

3.2 Annual variation: Analytical modelling using sinusoidal functions

We spectrally decomposed the air and soil temperature series using Fourier analysis. The dominant signal is the one year period variation, and as expected, the power of the annual signal decreases with depth.

To assess the character of heat transport at the annual timescale we use the method described by Hurley and Wiltshire (1993) and applied by Smerdon et al. (2003) to data from North America.

On a certain time scale, if the air and soil temperature series can be assumed as sinusoidal functions of time, the surface temperature varies according to

$T(0, t)=T_{0}+\Delta T \cos (\omega t+\epsilon)$

where $T_{0}$ is the mean temperature, $\Delta T$ is the amplitude of the sinusoidal oscillation, $\omega$ is the angular frequency, and $\epsilon$ is the initial phase of the oscillation.
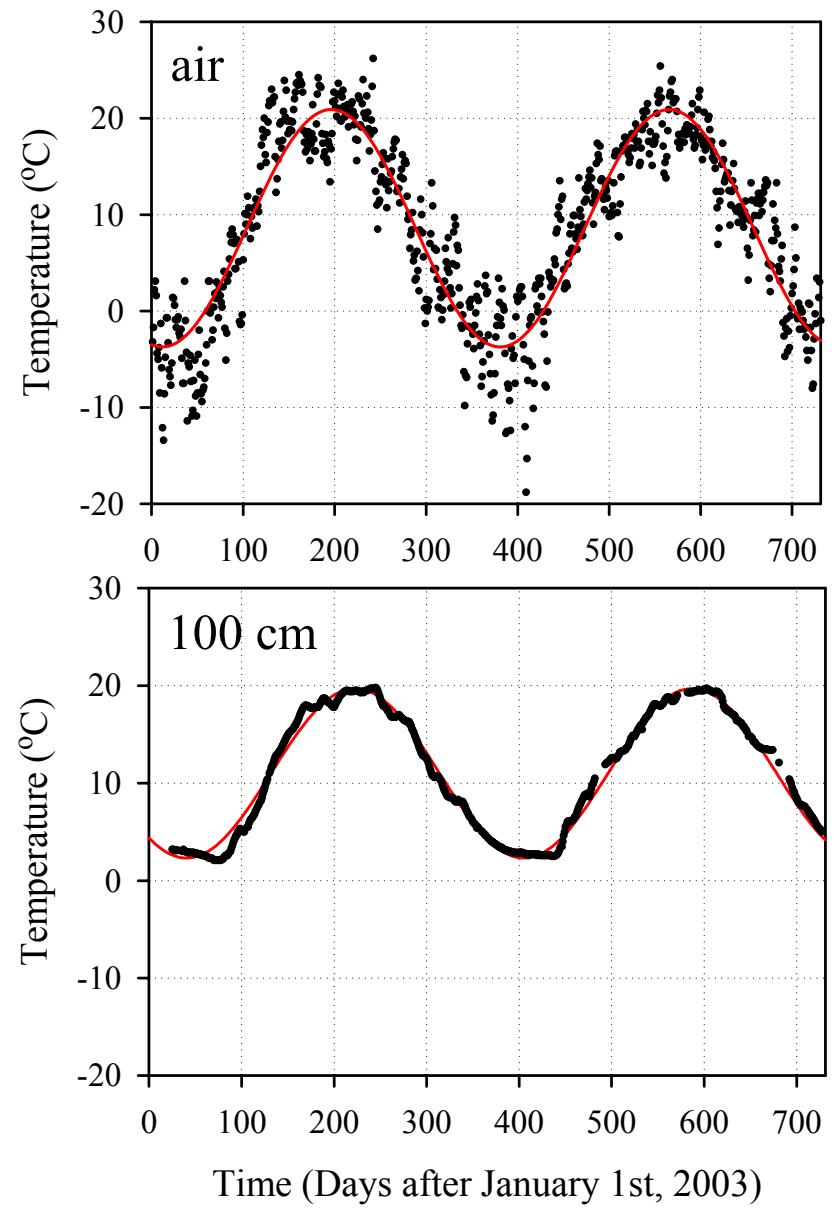

Fig. 10. Daily SAT and $100 \mathrm{~cm}$ soil temperatures recorded at Bistriţa station for 2003 and 2004. The sinusoidal function fit is illustrated with red line.

The time-dependent soil temperature fluctuation at depth $z$ is then described by Carslaw and Jaeger (1959):

$T(z, t)=T_{0}+\Delta T \exp \left(-z \sqrt{\frac{\omega}{2 \kappa}}\right) \cos \left(\omega t-z \sqrt{\frac{\omega}{2 \kappa}}+\epsilon\right)(4)$

The amplitude of the soil temperature fluctuation at depth $z$ is $A(z)=\Delta T \exp \left(-z \sqrt{\frac{\omega}{2 \kappa}}\right)$. The amplitude of the soil temperature variation decreases to $1 / e$ of its surface value at the depth $d_{e}=\sqrt{\frac{2 \kappa}{\omega}}$. The phase difference between temperature variations at the surface and any depth $z$ is given by $\phi(z)=z \sqrt{\frac{\omega}{2 \kappa}}$.

The amplitude and phase of the annual signal were calculated fitting the signal with a cosine function:

$y=y_{0}+a \cos \left(\frac{2 \pi}{b} t+c\right)$

where the parameters are the mean temperature, $y_{0}$, the amplitude, $a$, the period of oscillation, $b$, and the phase, $c$. An example is illustrated in Fig. 10 for the Bistriţa station. One 

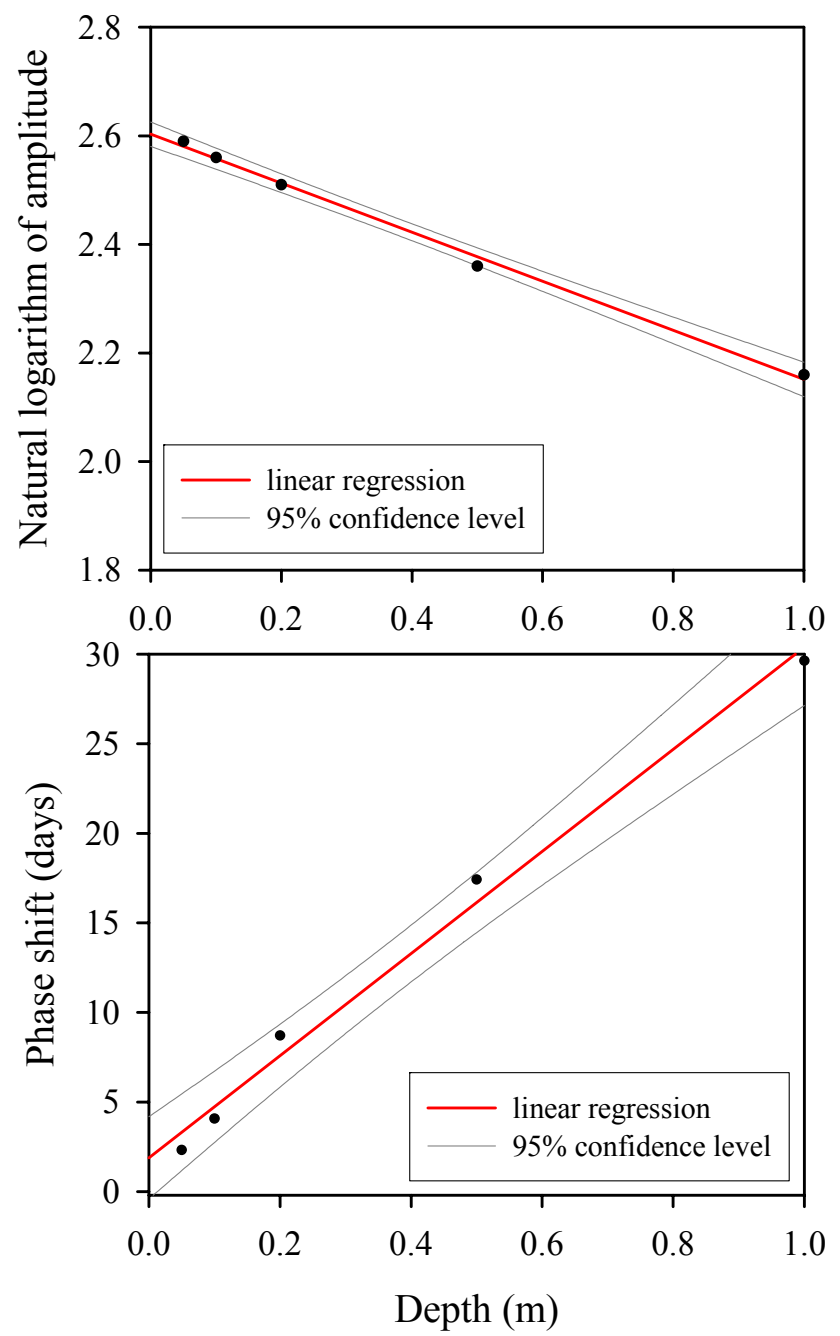

Fig. 11. Natural logarithm of amplitude and phase shift relative to the SAT as function of depth for Bistriţa. The coefficient of determination of the regression line is $r^{2}=0.996$ and $r^{2}=0.990$ for amplitude and phase shift, respectively. The $95 \%$ confidence interval is also included.

can easily see the attenuation with depth of the high frequency oscillations that are present in SAT. At one meter depth the measured signal is almost perfectly described by a sinusoidal function $\left(r^{2}=0.984\right)$.

To further investigate the conductive character of heat propagation into the soil, we plotted the natural logarithm of amplitude $\left(\ln A=\ln (\Delta T)-z \sqrt{\frac{\omega}{2 \kappa}}\right)$ and the phase shift as function of depth for Bistriţa (Fig. 11). The linear decrease with depth of the natural logarithm of amplitude and the linear increase with depth of the phase shift indicate conductive dominated heat transport.

The slope of the linear regression of both $\ln A(z)$ and $\phi(z)$ gives an estimate of the thermal diffusivity, $\kappa_{a}$ and $\kappa_{\phi}$, respectively, for the uppermost one meter of soil. The results for 8 stations are presented in Table 2. Because of miss-
Table 2. Amplitude of annual surface temperature, in ${ }^{\circ} \mathrm{C}$, and thermal diffusivity $\kappa_{A}$ and $\kappa_{\phi}$, in $10^{-7} \mathrm{~m}^{2} \mathrm{~s}^{-1}$, for the first meter of soil obtained from the sinusoidal treatment. $\bar{\kappa}$ is the average thermal diffusivity $\left(\left(\kappa_{A}+\kappa_{\phi}\right) / 2\right)$.

\begin{tabular}{lcccc}
\hline Station & $A_{\text {surface }}($ fitted $)$ & $\kappa_{A}$ & $\kappa_{\phi}$ & $\bar{\kappa}$ \\
\hline Adamclisi & 13.48 & 4.36 & 3.33 & $3.85 \pm 0.52$ \\
Bistriţa & 14.23 & 4.89 & 4.16 & $4.53 \pm 0.37$ \\
Oradea & 13.60 & 4.63 & 4.10 & $4.37 \pm 0.27$ \\
Satu Mare & 14.30 & 3.67 & 5.21 & $4.44 \pm 0.77$ \\
Slobozia & 14.83 & 9.89 & 8.81 & $9.35 \pm 0.54$ \\
Tg. Jiu & 14.57 & 5.41 & 5.28 & $5.35 \pm 0.07$ \\
Tg. Mureş & 14.87 & 2.94 & 2.50 & $2.72 \pm 0.22$ \\
Vaslui & 14.27 & 4.87 & 4.59 & $4.73 \pm 0.14$ \\
\hline
\end{tabular}

ing data, Roman and Reşiţa stations could not be used for this analysis. There is a good correlation between the values of diffusivity $\left(r^{2}=0.843\right)$ obtained with the two regression curves, but diffusivities computed from the $\ln A$ curve are generally larger. The difference to their mean value $(\bar{\kappa})$ is less than $\pm 10 \%$, except for Adamclisi and Satu Mare stations ( $\pm 13 \%$ and $\pm 17 \%$, respectively,). A $10 \%$ variation of $\kappa_{a}$ implies a rms difference in the annual temperature signal propagating into the uppermost one meter of soil of less than $0.2 \mathrm{~K}$. This difference is negligible when compared to the amplitude of the annual temperature wave (around $12^{\circ} \mathrm{C}$ at the surface and $7^{\circ} \mathrm{C}$ at one meter depth). At Adamclisi, the marginally larger difference between $\kappa_{A}$ and $\kappa_{\phi}$ can be explained by a weaker definition of the sinusoid for the depth of $1 \mathrm{~m}$, because of missing data. We do not have, however, a satisfactory explanation for the Satu Mare case.

\section{Conclusions}

The Romanian weather network data show that:

1. The heat transfer down to one meter depth is influenced by non-conductive processes such as phase changes. The zero-curtain and the snow thermo-insulation effects are present in data, as shown by recorded temperatures to depths of $20 \mathrm{~cm}$ and derived thermal gradients;

2. At the daily time-scale, qualitative assessment by means of perpendicular superposition of temperature records at various depths shows the presence of non-conductive processes disturbing an ideal conductive environment down to $1 \mathrm{~m}$ depth, though more pronounced in the uppermost $50 \mathrm{~cm}$ of the subsurface. Simple conductive models cannot reproduce recorded soil temperatures during the freezing season or during the summer. Incorporating latent heat contribution to the heat transfer in the active layer is a necessary step; 
3. At the seasonal time-scale, an effective variable thermal diffusivity for the first meter could be defined. The variation of the water content of soil was identified as a source of thermal diffusivity variations, even in case of the $50-100 \mathrm{~cm}$ depth range;

4. The annual signal in data represented by sinusoidal fit to measured values is controlled, in the first meter of soil, by heat conduction; the effective thermal diffusivities for 8 stations with continuous time series at all depth levels range from 3 to $10 \times 10^{-7} \mathrm{~m}^{2} \mathrm{~s}^{-1}$;

5. Detailed studies on heat transfer through the upper meter of the ground at the 1 day time-scale would be possible upon changes in data acquisition protocol which, at present consists of four temperature records per day.

Acknowledgements. The study has been supported by the Institute of Geodynamics (Projects 2/2004-2005) and the Ministry of Education and Research (Projects CERES 3-26/2003, MENER 405/2004). We thank J. C. Mareschal, M. Tumanian, M. Verdoia and an anonymous reviewer for comments and suggestions that helped us improve this paper.

Edited by: V. Rath

\section{References}

Bartlett, M. G., Chapman, D. S., and Harris, R. N.: Snow and the ground temperature record of climate change, J. Geophys. Res., 109, F04008, doi:10.1029/2004JF000224, 2004.

Bartlett, M. G., Chapman, D. S., and Harris, R. N.: Snow effect on North American ground temperatures, 1950-2002, J. Geophys. Res., 110, F03008, doi:10.1029/2005JF000293, 2005.

Beltrami, H.: On the relationship between ground temperature histories and meteorological records: a report on the Pomquet station, Global Planet. Change, 29, 327-349, 2001.

Beltrami, H.: Climate from borehole data: Energy fluxes and temperatures since 1500, Geophys. Res. Lett., 29, 2111, doi:10.1029/2002GL015702, 2002.

Beltrami, H. and Kellman, L.: An examination of short-and longterm air-ground temperature coupling, Global Planet. Change, 38, 291-303, 2003.

Boroneanţ, C., Ioniţã, M., and Dumitrescu, A.: Trends and shifts in the seasonal temperature mean in Romania during the period 1961-2000, International Workshop "Significant Scientific Research on Global Environmental Change in Central and Eastern Europe", Sinaia, 6-8 October, 2004.

Briffa, K. R. and Osborn, T. J.: Blowing hot and cold, Science, 295, 2227-2228, 2002.

Carslaw, H. S. and Jaeger, J. C.: Conduction of Heat in Solids, 2nd ed., Oxford Univ. Press, New York, 1959.

Chapman, D. S., Bartlett, M. G., and Harris, R. N.: Comment on "Ground vs. surface air temperature trends: Implications for borehole surface temperature reconstructions" by Mann M. E. and Schmidt G., Geophys. Res. Lett., 31, L07205, doi:10.1029/2003GL019054, 2004.

Demetrescu, C., Nitoiu, D., Boroneanţ, C., Marica, A., and Lucaschi, B.: Preliminary analysis of two-year long records of air and underground temperatures as measured at automatic weather stations in Romania, Rev. Rom. Geophys., 50, 99-106, 2006.

Esper, J., Cook, E. R., and Schweingruber, F. H.: Lowfrequency signals in long tree-ring chronologies for reconstructing past temperature variability, Science, 295, 2250-2253, doi:10.1126/science.1066208, 2002.

Esper, J., Frank, D. C., and Wilson, R. J. S.: Climate reconstructions: low-frequency ambition and high-frequency ratification, EOS, 85, 113, p. 120, 2004.

González-Rouco, J. F., von Storch, H., and Zorita, E.: Deep soil temperature as proxy for surface air-temperature in a coupled model simulation of the last thousand years, Geophys. Res. Lett., 30, 2116-2119, 2003.

González-Rouco, J. F., Beltrami, H., Zorita, E., and von Storch, H.: Simulation and inversion of borehole temperature profiles in surrogate climates: Spatial distribution and surface coupling, Geophys. Res. Lett., 33, L01703, doi:10.1029/2005GL024693, 2006.

Grundstein, A., Todhunter, P., and Mote, T.: Snowpack control over the thermal offset of air and soil temperatures in eastern North Dakota, Geophys, Res. Lett., 32, L08503, doi:10.1029/2005GL022532, 2005.

Harris, R. and Chapman, D.: Geothermics and climate change 1.Analysis of borehole temperatures with emphasis on resolving power, J. Geophys. Res., 103(B4), 7363-7360, 1998.

Hegerl, G. C., Crowley, T. J., Allen, M., Hyde, W. T., Pollack, H. N., Smerdon, J. E., and Zorita, E.: Detection of human influence on a new, validated 1500-year temperature reconstruction, J. Climate, 20, 650-666, 2007.

Huang, S., Pollack, H. N., and Shen, P. Y.: Temperature trends over the last five centuries reconstructed from borehole temperatures, Nature, 403, 756-758, 2000.

Hurley, S. and Wiltshire, R. J.: Computing thermal diffusivity from soil temperature measurements, Computers and Geosciences, 19, 475-477, 1993.

Kane, D., Hinkel, K., Goering, D., Hinzman, L., and Outcalt, S.: Non-conductive heat transfer associated with frozen soils, Global Planet. Change, 29, 275-292, 2001.

Mann, M. E., Rutherford, S., Bradley, R. S., Hughes, M. K., and Keiming, F. T.: Optimal surface temperature reconstructions using terrestrial borehole data, J. Geophys. Res., 108(D7), 4203, doi:10.1029/2002JD002532, 2003.

Mann, M. E. and Schmidt, G. A.: Ground vs. surface air temperature trends: Implications for borehole surface temperature reconstructions, Geophys. Res. Lett., 30, 1607, doi:10.1029/2003GL017170, 2003.

McIntyre, S. and McKitrick, R.: Hockey sticks, principal components, and spurious significance, Geophys. Res. Lett., 32, L03710, doi:10.1029/2004GL021750, 2005.

Nitoiu, D. and Beltrami, H.: Subsurface thermal effects of land use changes, J. Geophys. Res., 110, F01005, doi:10.1029/2004JF000151, 2005.

Nitoiu, D.: Ground surface temperature history reconstruction from geothermal data and the influence of land disruptions on the subsurface temperature profiles, MSc Thesis, St. Francis Xavier University, 2005.

Oke, T. R.: Boundary Layer Climates, Second Edition, Cambridge University Press, 1987.

Pollack, H. N. and Smerdon, J. E.: Borehole climate reconstruc- 
tions: Spatial structure and hemispheric averages, J. Geophys. Res., 109, D11106, doi:10.1029/2003JD004163, 2004.

Pollack, H. N., Smerdon, J. E., and van Keken, P. E.: Variable seasonal coupling between air and ground temperatures: A simple representation in terms of subsurface thermal diffusivity, Geophys. Res. Lett., 32, L15405, doi:10.1029/2005GL023869, 2005.

Putnam, S. N. and Chapman, D. S.: A geothermal climate change observatory: First year results from Emigrant Pass in northwest Utah, J. Geophys. Res., 101, 21 877-21 890, 1996.

Romanovsky, V. E. and Osterkamp, T. E.: Effects of unfrozen water on heat and mass transport processes in the active layer and permafrost, Permafrost Periglac. Process., 11, 219-239, 2000.

Schmidt, W. L., Gosnold, W. D., and Enz, J. W.: A decade of airground temperature exchange from Fargo, North Dakota, Global Planet. Change, 29, 311-325, 2001.

Smerdon, J. E., Pollack, H. N., Enz, J. W., and Lewis, M. J.: Conduction dominated heat transport of the annual temperature signal in soil, J. Geophys. Res., 108(B9), 2431, doi:10.1029/2002JB002351, 2003.

Smerdon, J. E., Pollack, H. N., Cermak, V., Enz, J. W., Kresl, M., Safanda, J., and Wehmiller, J. F.: Air-ground temperature coupling and subsurface propagation of annual temperature signals, J. Geophys. Res., 109, D21107, doi:10.1029/2004JD005056, 2004.

Smerdon, J. E., Pollack, H. N., Cermak, V., Enz, J. W., Kresl, M., Safanda, J., and Wehmiller, J. F.: Daily, seasonal and annual relationships between air and subsurface temperatures, J. Geophys. Res.-Atmos., 111, D07191, doi:10.1029/2004JD005578, 2006.
Sokratov, S. A. and Barry, R. G.: Intraseasonal variation in the thermoinsulation effect of snow cover on soil temperature and energy balance, J. Geophys. Res., 107(D10), doi:10.1029/2001JD000489, 2002.

Stevens, M. B., González-Rouco, J. F., and Beltrami, H.: North American climate of the last millennium: Underground temperatures and model comparison, J. Geophys. Res., 2006JF000705, in press, 2007.

Stieglitz, M., Dery, S. J., Romanovsky, V. E., and Osterkamp, T. E.: The role of snow cover in the warming of arctic permafrost, Geophys. Res. Lett., 30, 1721, doi:10.1029/2003GL017337, 2003.

Şerban, D., Nielsen , S., and Demetrescu, C.: Long wavelength ground surface temperature history from continuous temperature logs in the Transylvanian Basin, Global Planet. Change, 29, 201217, 2001.

Trenberth, K. E. and Shea, D. J.: Relationships between precipitation and surface temperature, Geophys. Res. Lett., 32, L14703, doi:10.1029/2005GL022760, 2005.

Ţîştea, D., Dincă, I., Cazacu, G., Sîrbu, V., Călinescu, N., Neamu, G., and Teodoreanu, E.: Air temperature map, in Atlas Republica Socialistă România, Romanian Academy Publishing House, 1979.

Yoshikawa, K., Bolton, W. R., Romanovsky, V. E., Fukunda, M., and Hinzman, L. D.: Impacts of wildfire on the permafrost in the boreal forests of Interior Alaska, J. Geophys. Res., 108, 8148, doi:10.1029/2001JD000438, 2003. 